http://www.jfas.info

\title{
EXPERIMENTAL AND NUMERICAL INVESTIGATION OF V-SHAPE PLATES SUBJECTED TO BLAST LOADINGS
}

\author{
M. N. Hafizi ${ }^{1,2^{*}}$, M. S. Risby ${ }^{1}$, S. T. Umar ${ }^{1}$, A. S. M. Sohaimi ${ }^{1}$, S. Khalis ${ }^{1}$ and K. S. Tan ${ }^{1}$ \\ ${ }^{1}$ Protection and Survivability Research Unit (PROTECT), Faculty of Engineering, Universiti \\ Pertahanan Nasional Malaysia, Sungai Besi Camp, 57000 Kuala Lumpur, Malaysia \\ ${ }^{2}$ Centre for Defence Research and Technology, Universiti Pertahanan Nasional Malaysia, \\ Sungai Besi Camp, 57000 Kuala Lumpur, Malaysia
}

Published online: 10 September 2017

\begin{abstract}
This paper presents the experimental and numerical investigation of angled shape metal plates response when subjected to an air blast loading. V shaped plates were fabricated at angles of $90^{\circ}, 120^{\circ}$ and $150^{\circ}$ respectively. The charge weight of $1 \mathrm{~kg}$ (PE4) was used to create a spherical blast wave at several standoff configurations. The experimental results were then compared with the numerical simulation model computed using LSDYNA3D.
\end{abstract}

Keywords: deflector; armoured vehicle; landmine; detonation; explosive.

Author Correspondence, e-mail: mohdhafizi@upnm.edu.my

doi: $\underline{\text { http://dx.doi.org/10.4314/jfas.v9i3s.18 }}$

\section{INTRODUCTION}

There are several published works that have reported the response of metal plate when subjected to blast loadings [1-10]. Most of researchers studied about the V shaped vehicle hull which is commonly known able to deflect blast wave emitted from landmine detonation $[4,6$, 9, 11-13]. In [11] have conducted experiments to study the difference angle of "V" structured 
plates from blast loading effect. In $[11,13]$ have reported the attenuation analysis of "V" hulls blast test results subjected to explosive charge and also have studied different plate angles varying from 140 to 180 degrees with standoff distance level from 0 to 1.5 inches. The explosive weight used was $0.636 \mathrm{~g}$ and was buried underground to represent landmine attacks. Besides that, other researchers have [4, 13-20] formulated a 2D and 3D computational patterns to analyze the blast attack on vehicle structures. However, there a few studies have been found to correlate the experimental findings with numerical simulation results. This paper presents the experimental and numerical investigation on several ' $\mathrm{V}$ ' shape plates (with different angles) subjected to a spherical air blast loading. The experimental data obtained in terms of deflection was compared with the numerical simulation for verification purposes.

\section{RESULTS AND DISCUSSION}

The experimental results are as shown in Table 1. From this results, it can be observed that 150-degree V plate exhibited the highest deflection of $120 \%$ whereas 90-degree V plate showed the lowest $\mathrm{V}$ plate deflection of $40 \%$ can be observed that at 90 -degree and 120-degree V plate angle provide a substantial resistance which was observed made from the deformed plates (deflection) compared to 150-degree V plate angle. This observation is in agreement with the results by [11]. Fig. 1 shows the different deflection depth on the "V" shape at a cross sectional view.

Table 1. Blast loading results

\begin{tabular}{cccccccc}
\hline & \multicolumn{3}{c}{ Charge } & \multicolumn{5}{c}{ Deflection on the Mid-Point (mm) } \\
$\begin{array}{c}\text { Angle } \\
(\mathbf{9})\end{array}$ & $\begin{array}{c}\text { Weight } \\
(\mathbf{k g})\end{array}$ & $\begin{array}{c}\text { Thickness } \\
(\mathbf{m m})\end{array}$ & $\begin{array}{c}\text { Standoff } \\
\mathbf{( m m})\end{array}$ & Origin & $\begin{array}{c}\text { After } \\
\text { Blast }\end{array}$ & Deflection & $\begin{array}{c}\text { Percentage } \\
\text { Different }\end{array}$ \\
& $\mathbf{P E 4}$ & & & & & & \\
\hline 90 & 2 & 2 & 1000 & 0.4331 & 0.2586 & 0.1745 & $40 \%$ \\
120 & 2 & 2 & 1000 & 0.3048 & 0.1155 & 0.1893 & $54 \%$ \\
150 & 2 & 2 & 1000 & 0.1578 & -0.0387 & 0.1965 & $120 \%$ \\
\hline
\end{tabular}

The 90-degree $\mathrm{V}$ plate experimental results were used as verification data for the finite element simulation. Fig. 2 shows that the simulated V plate deformation are near similar to 
the observed deformation of the tested V plate.

\subsection{Numerical Simulation Result}

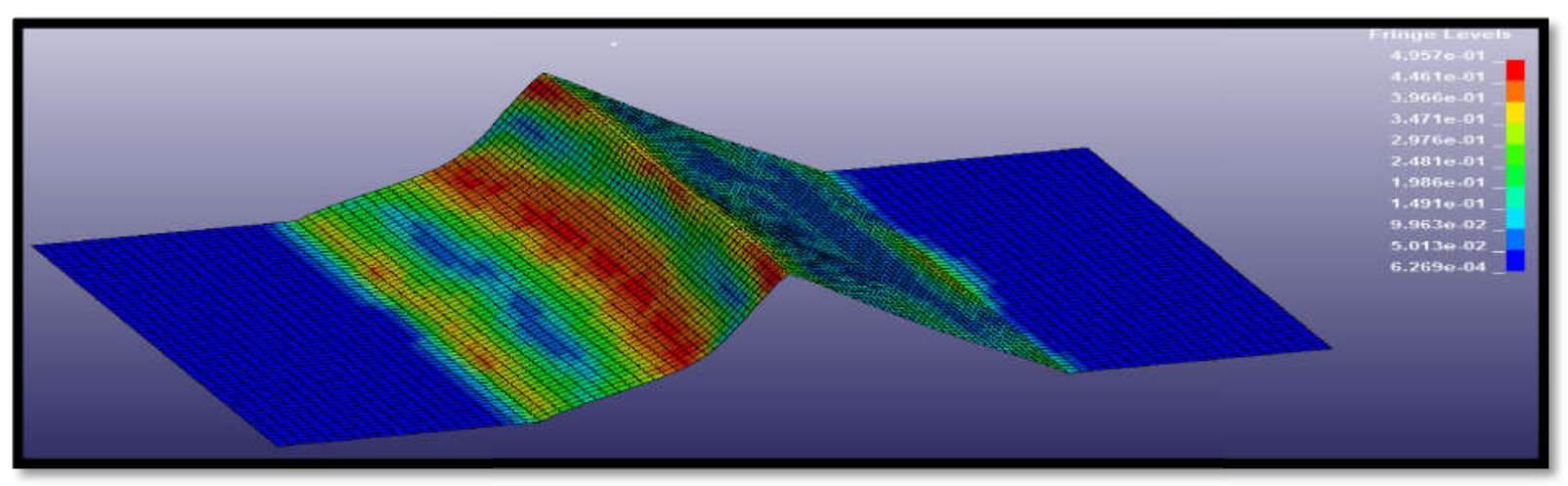

(a)

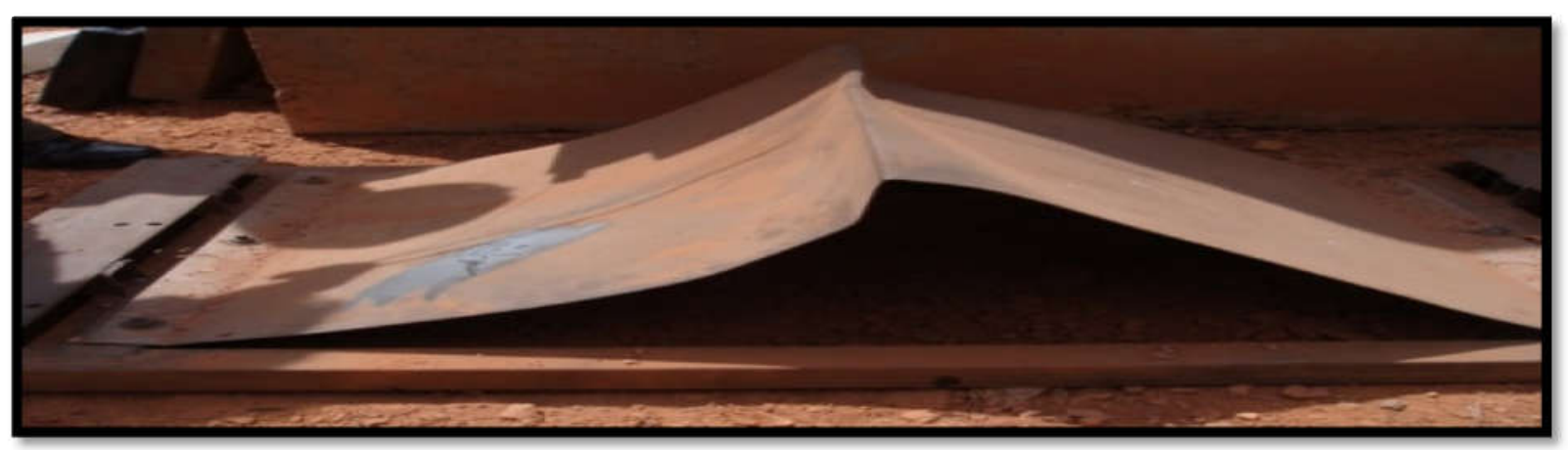

(b)

Fig.1. Photograph showing simulation and experiment failure; (a) LSDYNA 3D simulation model, (b) experimental image after blast load

Fig. 2 shows the computed deflection of the 90 degree, 120-degree and 150-degree of V plates using 2 types of material models. The computed results were compared with the experimental data for verification purposes. Based for the results, the computed 120-degree and 150-degree of $\mathrm{V}$ plate results shows near similarity in terms of deflection curve compared to 90-degree. It can be assumed that during blast testing, the plastic explosive may not perfectly have placed in line with the mid plane of the $\mathrm{V}$ plate, thus producing a non-uniformity pressure loading to the V plate structure. 


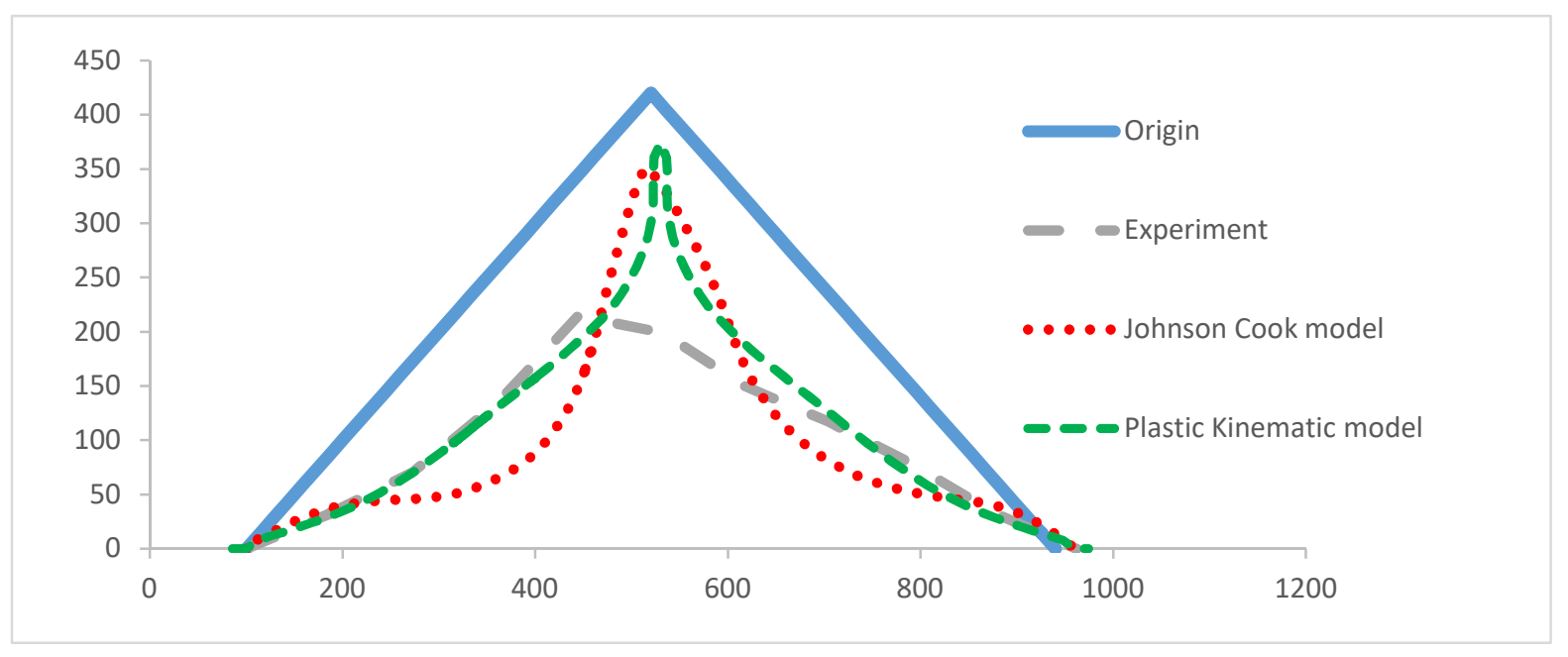

(a)

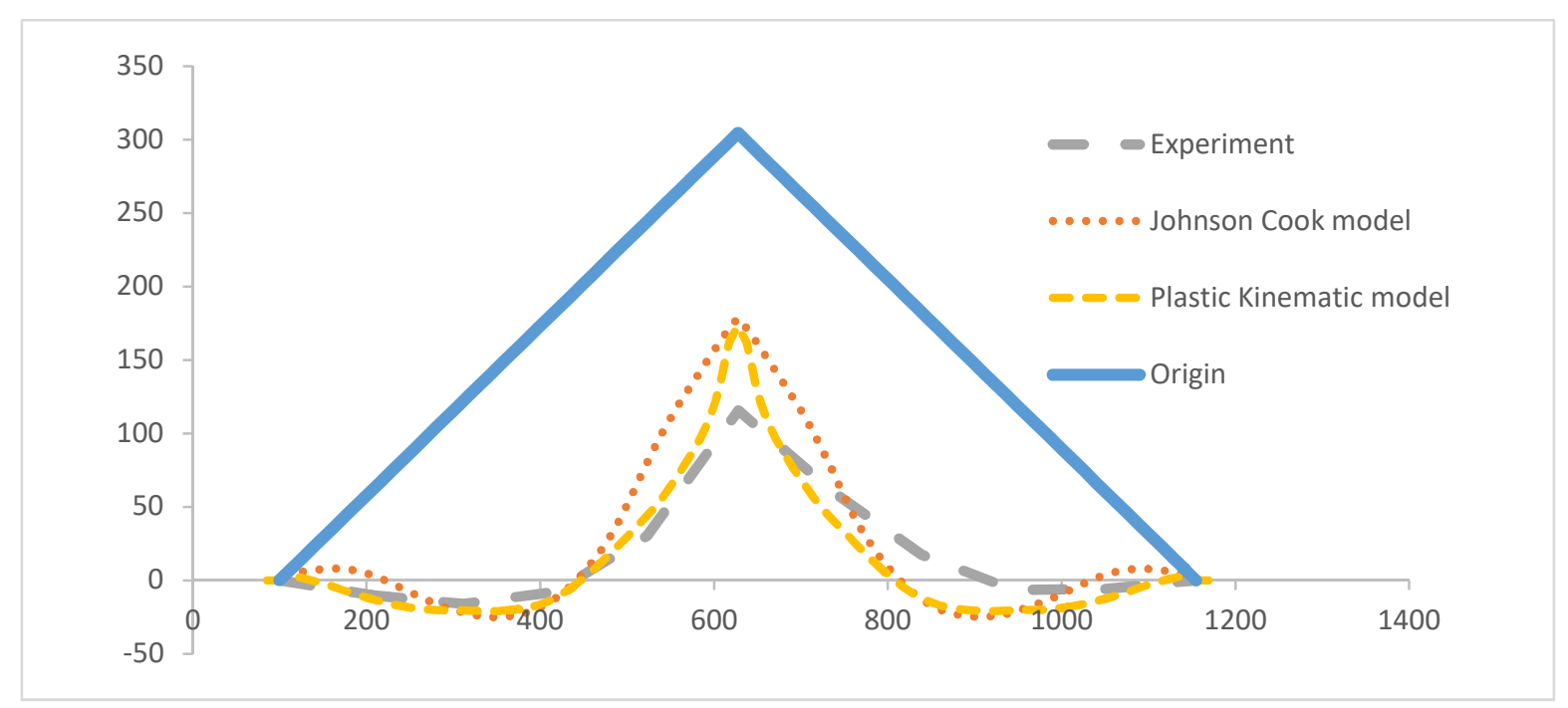

(b)

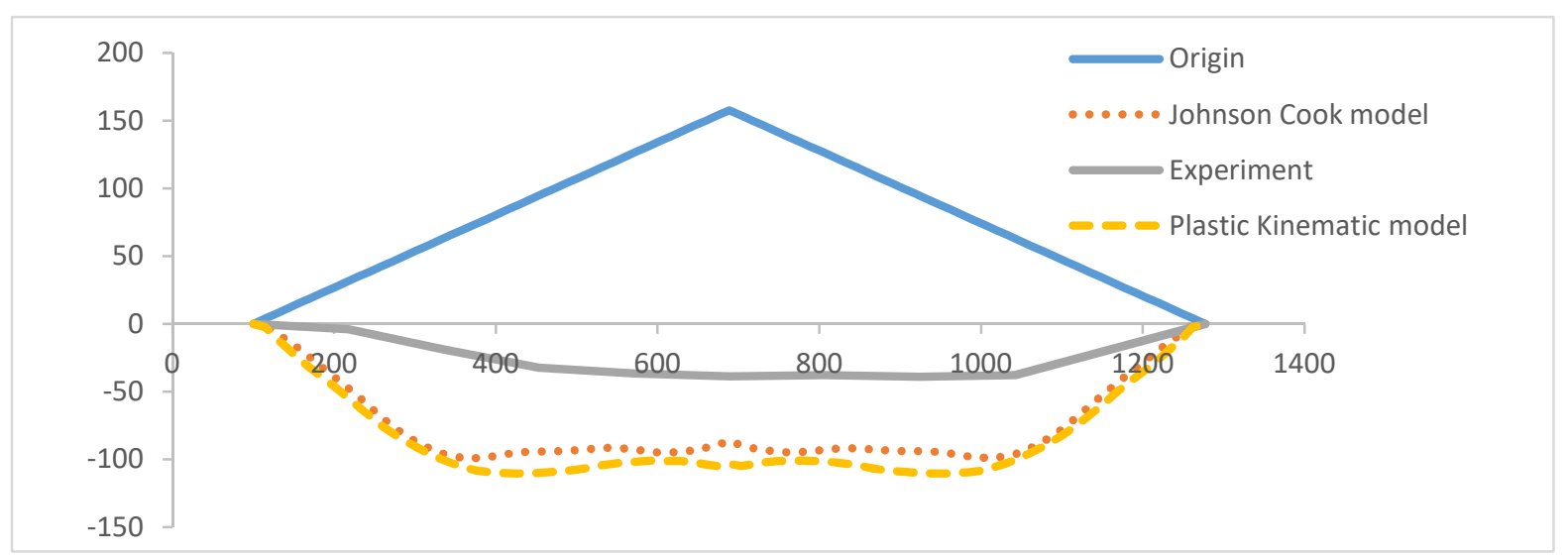

(c)

Fig.2. Deflection after blast loading, experiment, Johonson Cook model and Plastic Kinematic model (a) $90^{\circ}$ angle (b) $120^{\circ}$ angle and (c) $150^{\circ}$ angle 
Fig. 3 represents a comparison by outcomes for cross sectional deflection of the V plates when using two different material model functions. Based from Table 2, it can be observed that Johnson Cook material model provide the nearest value when compared with the experimental results. This may be due that for blast modeling the material model should be capable of predicting the flow stress as a function of plastic strain, strain rate, temperature and provide a comprehensive description for a progressive ductile failure model. The Johnson Cook material model is favoured due to the multiple functions available in the material model compared to a much simple Plastic Kinematics model.

Table 2. Comparison of mid plane deflection from experiment and simulation results

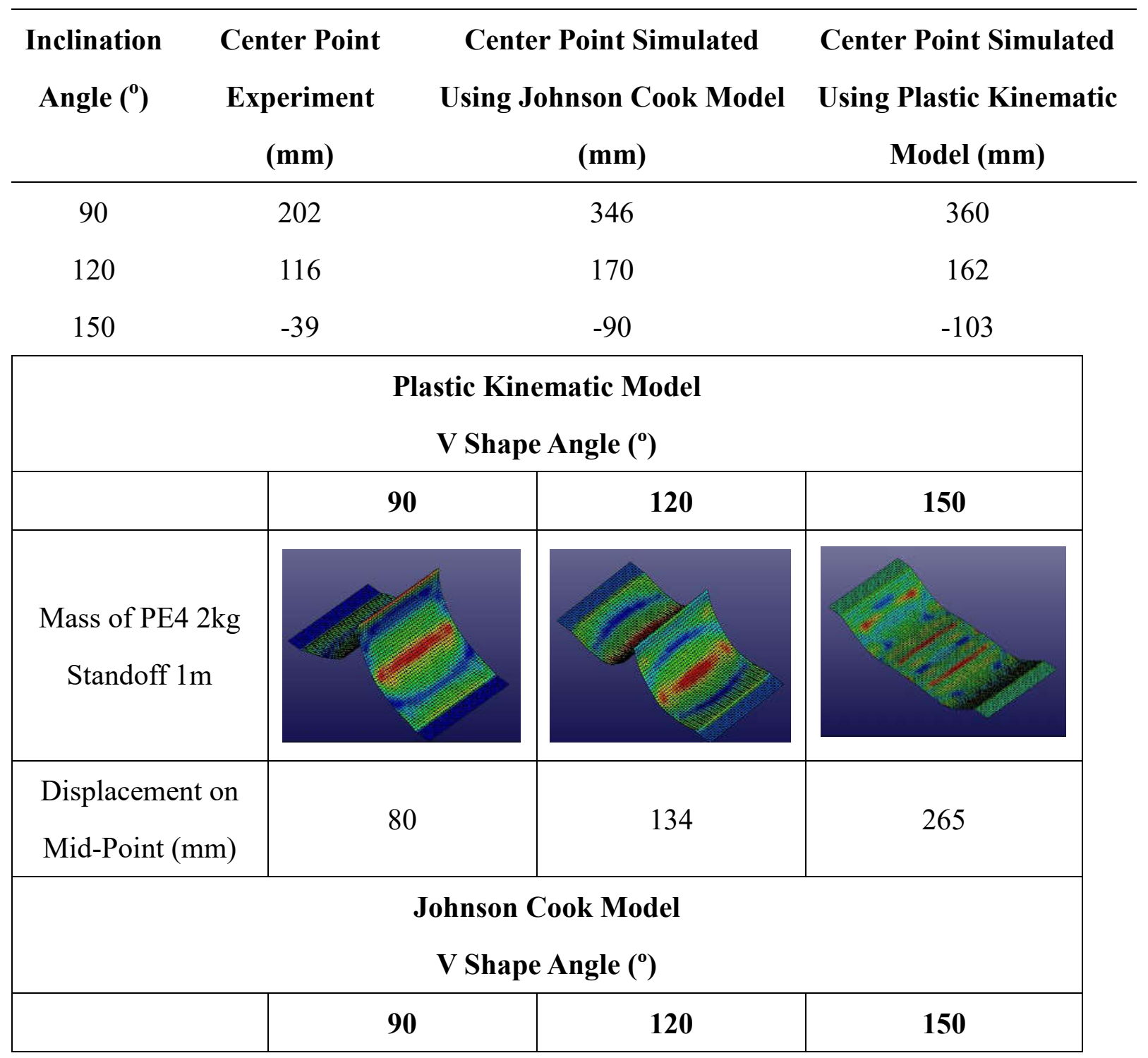




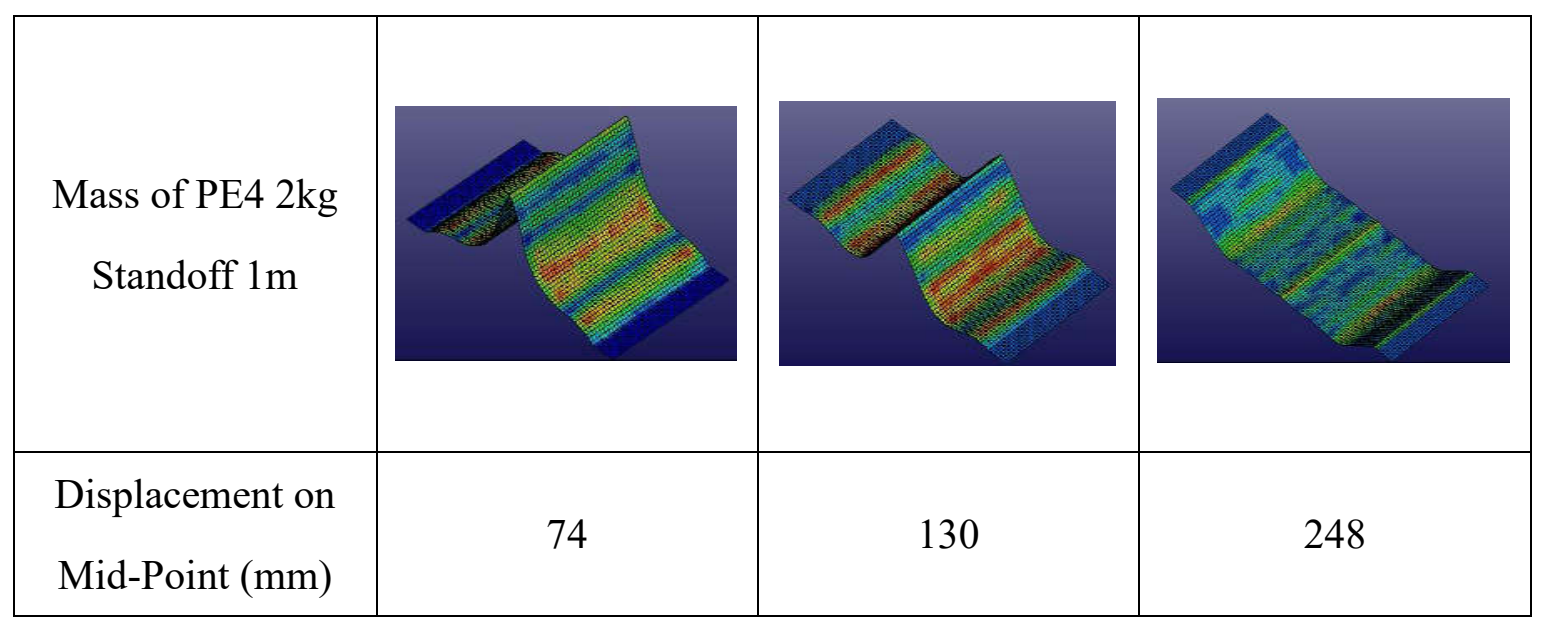

Fig.3. Contours of displacement between Plastic Kinematic model and Johnson Cook model

\section{EXPERIMENTAL}

\subsection{Experiment Setup}

Three metal plates of different V shape angles were fabricated which are (a) $90^{\circ}$, (b) $120^{\circ}$ and (c) $150^{\circ}$ respectively. Fig. 4 shows the test setup for the plates where a plastic explosive is placed vertically 1 meter on top of the mid plane of the plate. The properties of the plastic explosive (PE4) is as shown in Table 3.

Table 3. Properties of explosive PE4 [21]

\begin{tabular}{cc}
\hline Description & Values \\
\hline Material & $2 \mathrm{~kg} \mathrm{PE} 4$ \\
Explosive Density & $1600 \mathrm{~kg} / \mathrm{m}^{3}$ \\
Explosive Internal Energy & $3.2 \times 10^{10} \mathrm{~kg} \cdot \mathrm{m}^{2} / \mathrm{s}^{2}$ \\
\hline
\end{tabular}

Fig. 4 shows the actual test setup where the $\mathrm{V}$ plate was fixed (at both ends) into a rig and PE4 was moulded into a spherical shape. This is to ensure that during detonation, spherical air blast will propagate down towards the $\mathrm{V}$ plate mid-section. 


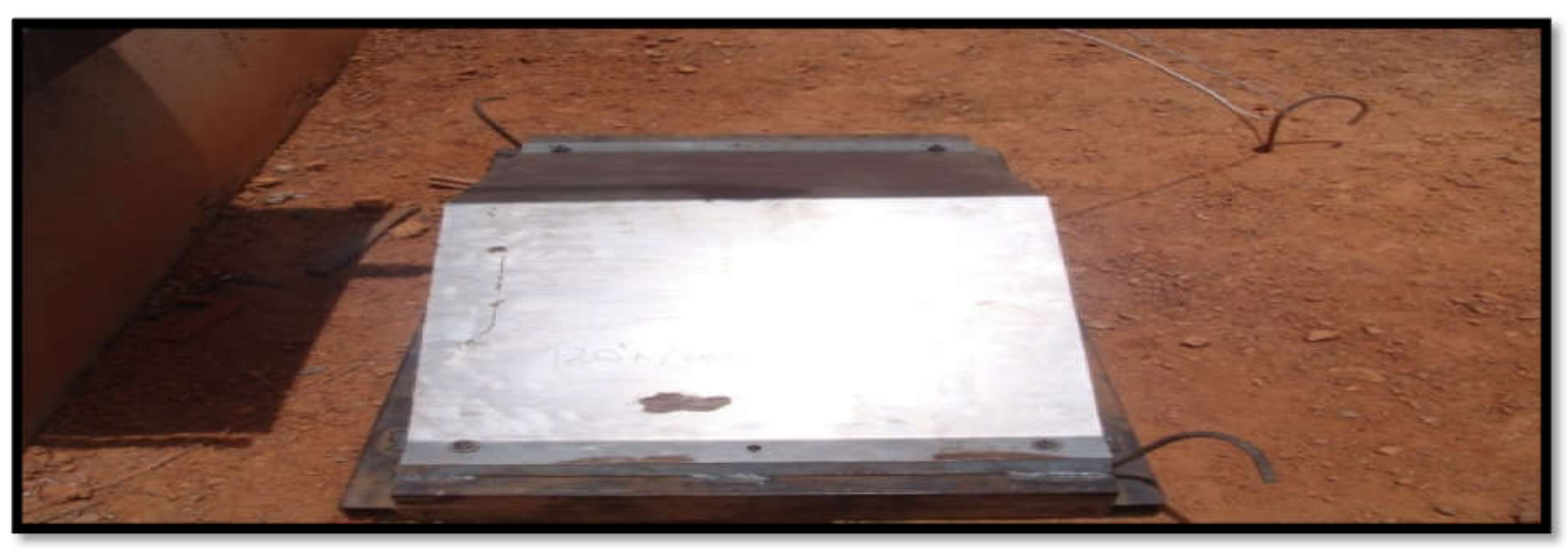

(a)

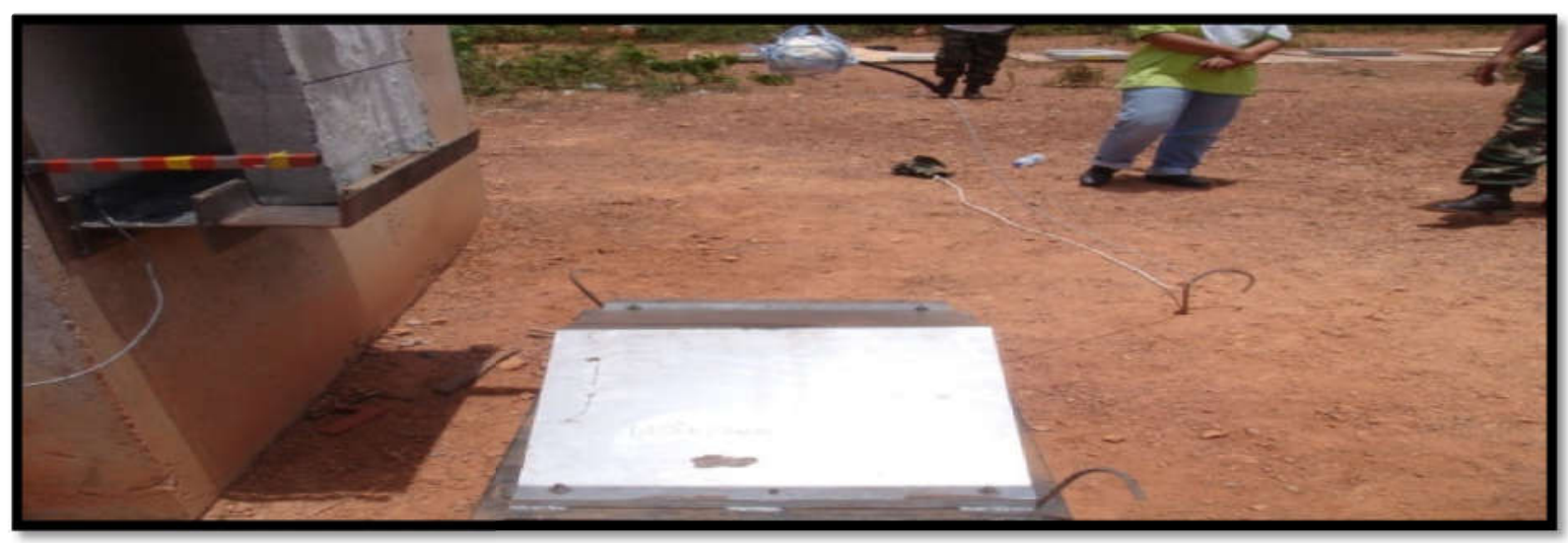

(b)

Fig.4. Experiment setup (a) V plate setup (b) standoff of explosive

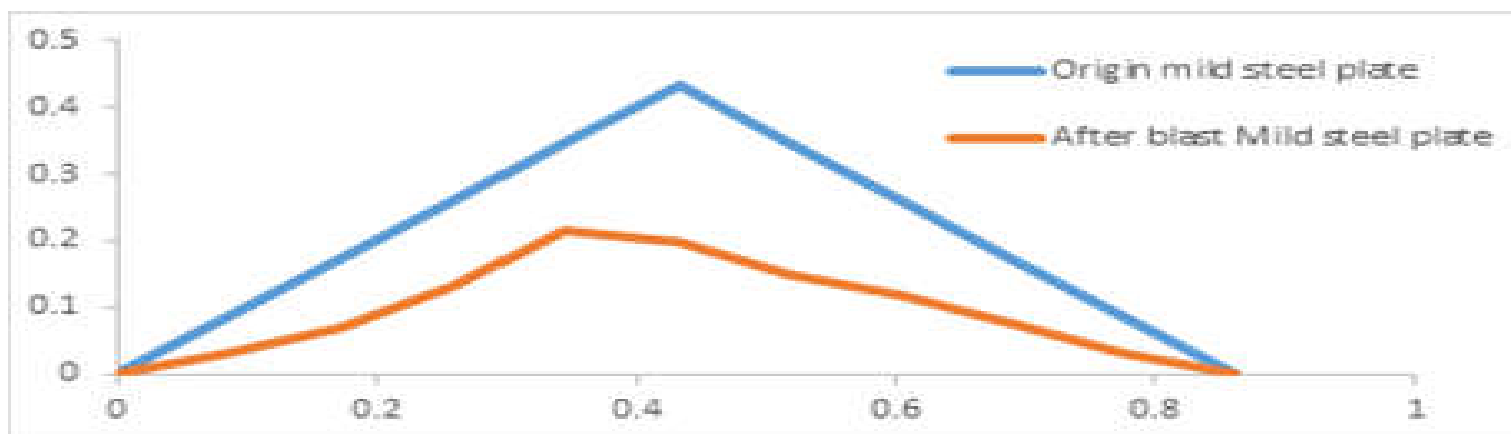

(a)

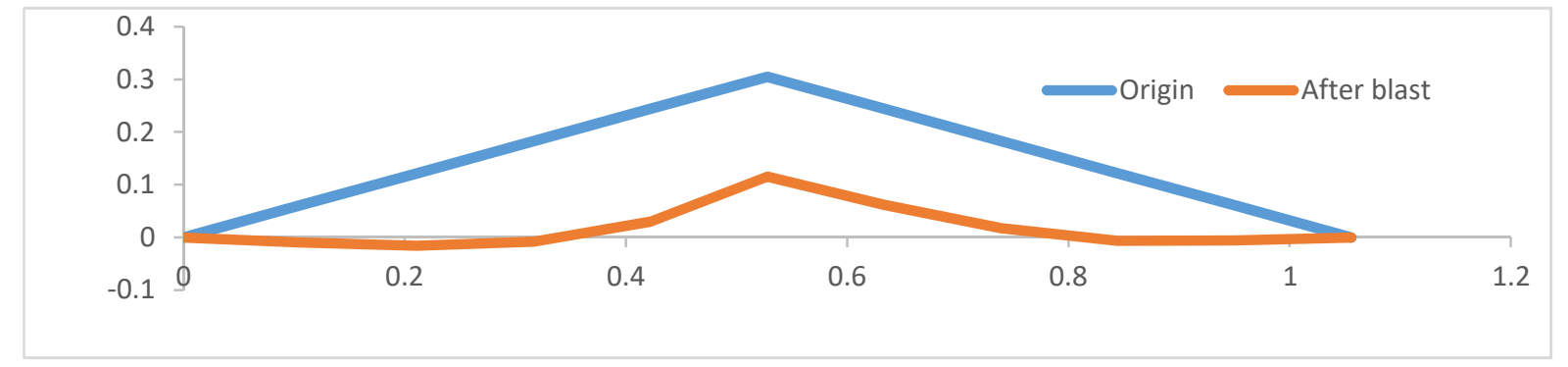

(b) 


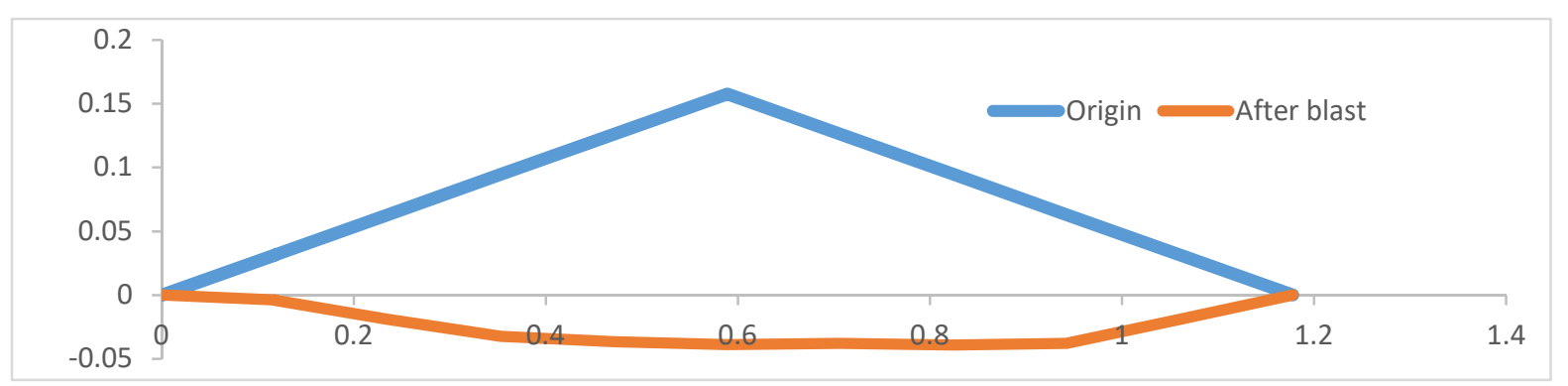

(c)

Fig.5. Deformation of the V plate after explosion (a) V plate $90^{\circ}$ (b) V plate with $120^{\circ}$ and (c) angle $150^{\circ}$ of plate

\subsection{Numerical Solution of V Plates}

The LSDYNA3D software was used to simulate V shape deflection when subjected to blast loading. The blast simulation was performed using Arbitrary Lagrange Euler (ALE) blast method available in LSDYNA3D function card. Fig. 5 shows the meshing process of V-shape plate model using of mild steel material's property. The $\mathrm{V}$ plate edges was fully restrained at the flat plane section in order to represent the clamped boundary conditions at the actual test rig.

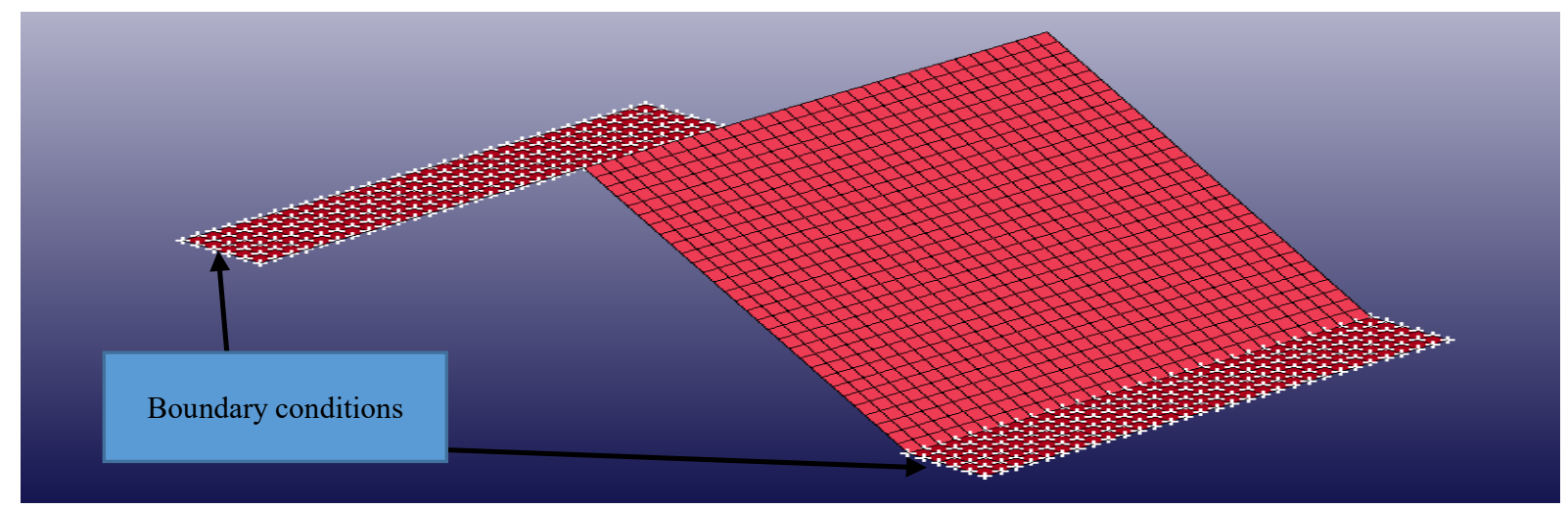

Fig.6. V shape plate $90^{\circ}$

\subsection{Properties and Failure Model for the V Shape Model}

The Johnson and Cook [22-24] material model is applied to the model. The Equation (1) and (2) as show the material flow stress as a function of strain, strain rate and temperature

$$
\begin{aligned}
& \bar{\sigma}=\left[A+B\left(\varepsilon^{-P I}\right)^{n}\right]\left[1+C \ln \left(\frac{\varepsilon \dot{p} l}{\dot{\varepsilon} 0}\right)\right]\left(1-\theta^{m}\right) \\
& \bar{\theta}^{m}=\left[\left(\frac{T-300 K}{\text { Tmelt }-300 K}\right)\right]
\end{aligned}
$$

where $\bar{\sigma}$ is the yield stress at non zero strain rate, $\varepsilon^{-P I}$ is the equivalent plastic strain, $\varepsilon p l$ 
is the normalized equivalent plastic strain rate, $\mathrm{T}$ is the material temperature $(\mathrm{K})$ and Tmelt is the melting temperature of the material. The constants $\mathrm{A}, \mathrm{B}, \mathrm{n}, \mathrm{C}$ and $\varepsilon 0$ are material dependent parameters and may be determined from an empirical fit of flow stress data. Table 4 lists the material dependent parameters used in the model [11], in this case material are using is mild steel.

Table 4. Material properties of mild steel [11]

\begin{tabular}{cccccc}
\hline A, Mpa & B, Mpa & n & C, $\mathbf{S}^{-\mathbf{1}}$ & m & Tmelt, $\mathbf{K}$ \\
\hline 217 & 234 & 0.643 & 0.017 & 0 & 373 \\
\hline
\end{tabular}

\section{CONCLUSION}

The difference geometries of the $\mathrm{V}$ shape plate $90^{\circ}, 120^{\circ}$ and $150^{\circ}$ degree and difference material model have been investigated using experimental and numerical approach. Based from the obtained results, $\mathrm{V}$ shape plate with angle $90^{\circ}$ and $120^{\circ}$ were found to deform significantly compared to $\mathrm{V}$ plates of $150^{\circ}$ angle. The numerical simulation results also concurred with the experimental findings and Johnson material model was found to compute results, which shows close similarity in terms of deflection values compared to Plastic Kinematic material model.

\section{ACKNOWLEDGEMENTS}

The authors wish to acknowledge the research grant provided by Long Term Research Grant Scheme (LRGS/B-U/2013/UPNM/DEFENCE\&SECURITY-P3) from the Malaysian Ministry of Education that lead to realization of this work.

\section{REFERENCES}

[1] Anderson C E, Behner T, Weiss C E. Mine blast loading experiments. International Journal of Impact Engineering, 2011, 38(8):697-706

[2] Denefeld V, Heider N, Holzwartha, Sättler A, Salk M. Reduction of global effects on vehicles after IED detonations. Defence Technology, 2014, 10(2):219-225

[3] Saeimi-Sadigh M A, Paykani A, Afkar A, Aminollah D. Design and energy absorption enhancement of vehicle hull under high dynamic loads. Journal of Central South University, 
2014, 21(4):1307-1312

[4] Maáachowski J. Effect of blast wave on chosen structure-Numerical and experimental study. International Journal of Mathematics and Computers in Simulation, 2008, 2:238-245

[5] Chan A, Chapman G, Hartman D, Lightweight composite integrated structural armor. 2009 ,

http://www.ocvreinforcements.com/hp/docs/2009_AUSA_HPR_armor_technical_white_pape r.pdf

[6] Ngo T, Mendis P, Gupta A, Ramsay J. Blast loading and blast effects on structures-An overview. Electronic Journal of Structural Engineering, 2007, 7(S1):76-91

[7] Feli S, Asgari M R. Finite element simulation of ceramic/composite armor under ballistic impact. Composites Part B: Engineering, 2011, 42(4):771-780

[8] Górniak a, Kaźmierczak a, Derlukiewicz D, Włostowski R. Numerical and experimental investigation of a movable wall response to a shock wave. Archives of Civil and Mechanical Engineering, 2014

[9] Ramasamy A, Hill A M, Hepper A E, Bull A M, Clasper J C. Blast mines: Physics, injury mechanisms and vehicle protection. Journal of the Royal Army Medical Corps, 2009, 155(4):258-264

[10] Ray N, Jagadeesh G, Suwas S. Response of shock wave deformation in AA5086 aluminum alloy. Materials Science and Engineering: A, 2015, 622:219-227

[11] Yuen S C, Langdon G S, Nurick G N, Pickering E G, Balden V H. Response of V-shape plates to localised blast load: Experiments and numerical simulation. International Journal of Impact Engineering, 2012, 46:97-109

[12] Courtney E, Courtney A, Courtney M. Shock tube design for high intensity blast waves for laboratory testing of armor and combat materiel. Defence Technology, 2014, 10(2):245-250

[13] Berger S, Ben-Dor G, Sadot O. Experimental and numerical investigations of shock-wave attenuation by geometrical means: A single barrier configuration. European Journal of Mechanics-B/Fluids, 2015, 50:60-70

[14] Dong L, Zhu F, Jin X, Suresh M, Jiang B, Sevagan G, Cai Y, Li G, Yang K H. Blast 
effect on the lower extremities and its mitigation: A computational study. Journal of the Mechanical Behavior of Biomedical Materials, 2013, 28:111-124

[15] Buonsanti M, Leonardi G. 3-D simulation of tunnel structures under blast loading. Archives of Civil and Mechanical Engineering, 2013, 13(1):128-134

[16] Priyadarshini A, Pal S K, Samantaray A K. Influence of the Johnson Cook material model parameters and friction models on simulation of orthogonal cutting process. Journal of Machining and Forming Technologies, 2012, 4(1/2):59-83

[17] Tan P. Numerical simulation of the ballistic protection performance of a laminated armor system with pre-existing debonding/delamination. Composites Part B: Engineering, 2014, 59:50-59

[18] Adams B. Simulation of ballistic impacts on armored civil vehicles. North Brabant: Eindhoven University of Technology, 2003

[19] Dolce F, Meo M, Wright A, French M, Bernabei M. Structural response of laminated composite plates to blast load. Plastics, Rubber and Composites, 2010, 39(3-5):180-188

[20] Zhang A, Wen-shan Y, Xiong-Liang Y. Numerical simulation of underwater contact explosion. Applied Ocean Research, 2012, 34:10-20

[21] Rigby S E, Sielicki P W. An investigation of TNT equivalence of hemispherical PE4 charges. Engineering Transactions, 2014, 4(62):423-435

[22] Gupta S, Abotula S, Shukla A. Determination of Johnson-Cook parameters for cast aluminum alloys. Journal of Engineering Materials and Technology, 2014, 136(3):1-4

[23] Vedantam K, Bajaj D, Brar N S, Hill S. Johnson-Cook strength models for mild and DP 590 Steels. AIP Conference Proceedings, 2006, 845(1):775-778

[24] Samantaray D, Mandal S, Bhaduri A K. A comparative study on Johnson Cook, modified Zerilli-Armstrong and Arrhenius-type constitutive models to predict elevated temperature flow behaviour in modified 9Cr-1Mo steel. Computational Materials Science, 2009, 47(2):568-576

\section{How to cite this article:}

Hafizi MN, Risby MS, Umar ST, Sohaimi ASM, Khalis S, Tan KS. Experimental and numerical investigation of v-shape plates subjected to blast loadings. J. Fundam. Appl. Sci., 2017, 9(3S), 210-220. 